\title{
THE BIG PICTURE
}

\section{Artist creates tribute to NHS superheroes}

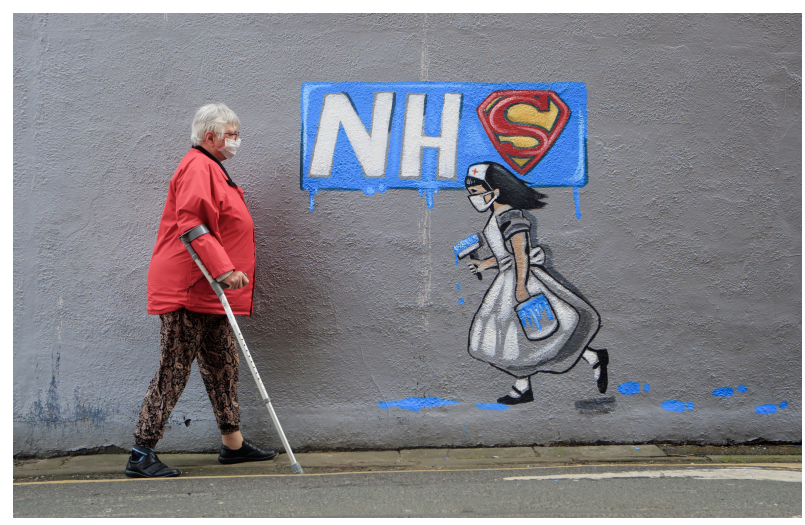

Yorkshire town as the UK continues in lockdown to try to curb the spread of covid-19.

[Image: Danny Lawson/PA]

The Pontefract artist Rachel List created this mural supporting the NHS on the side of the Horse Vaults pub in the West 